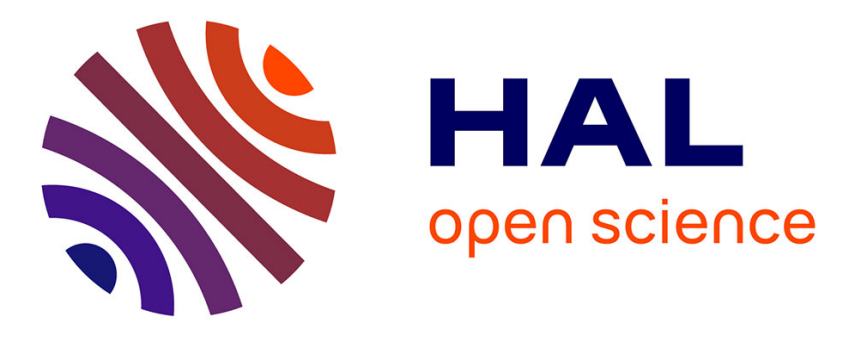

\title{
Bioavailability of the flavanone naringenin and its glycosides in rats
}

Catherine Felgines, Odile Texier, Christine Morand, Claudine Manach, Augustin Scalbert, Françoise Régerat, Christian Remesy

\section{To cite this version:}

Catherine Felgines, Odile Texier, Christine Morand, Claudine Manach, Augustin Scalbert, et al.. Bioavailability of the flavanone naringenin and its glycosides in rats. AJP - Gastrointestinal and Liver Physiology, 2000, 279 (6), pp.G1148-G1154. hal-02694848

\section{HAL Id: hal-02694848 https://hal.inrae.fr/hal-02694848}

Submitted on 1 Jun 2020

HAL is a multi-disciplinary open access archive for the deposit and dissemination of scientific research documents, whether they are published or not. The documents may come from teaching and research institutions in France or abroad, or from public or private research centers.
L'archive ouverte pluridisciplinaire HAL, est destinée au dépôt et à la diffusion de documents scientifiques de niveau recherche, publiés ou non, émanant des établissements d'enseignement et de recherche français ou étrangers, des laboratoires publics ou privés. 
Catherine Felgines, Odile Texier, Christine Morand, Claudine Manach, Augustin Scalbert, Françoise Régerat and Christian Rémésy

Am J Physiol Gastrointest Liver Physiol 279:1148-1154, 2000.

You might find this additional information useful...

This article cites 25 articles, 5 of which you can access free at:

http://ajpgi.physiology.org/cgi/content/full/279/6/G1148\#BIBL

This article has been cited by 7 other HighWire hosted articles, the first 5 are:

The Bioavailability of Apigenin-7-Glucoside Is Influenced by Human Intestinal Microbiota in Rats

L. Hanske, G. Loh, S. Sczesny, M. Blaut and A. Braune

J. Nutr., June 1, 2009; 139 (6): 1095-1102.

[Abstract] [Full Text] [PDF]

Bioavailability Is Improved by Enzymatic Modification of the Citrus Flavonoid Hesperidin in Humans: A Randomized, Double-Blind, Crossover Trial

I. L. F. Nielsen, W. S. S. Chee, L. Poulsen, E. Offord-Cavin, S. E. Rasmussen, H. Frederiksen,

M. Enslen, D. Barron, M.-N. Horcajada and G. Williamson

J. Nutr., February 1, 2006; 136 (2): 404-408.

[Abstract] [Full Text] [PDF]

Bioavailability and bioefficacy of polyphenols in humans. I. Review of 97 bioavailability studies

C. Manach, G. Williamson, C. Morand, A. Scalbert and C. Remesy

Am. J. Clinical Nutrition, January 1, 2005; 81 (1): 230S-242S.

[Abstract] [Full Text] [PDF]

The splanchnic metabolism of flavonoids highly differed according to the nature of the compound

V. Crespy, C. Morand, C. Besson, N. Cotelle, H. Vezin, C. Demigne and C. Remesy

Am J Physiol Gastrointest Liver Physiol, June 1, 2003; 284 (6): G980-G988.

[Abstract] [Full Text] [PDF]

Naringenin from Cooked Tomato Paste Is Bioavailable in Men

R. Bugianesi, G. Catasta, P. Spigno, A. D'Uva and G. Maiani

J. Nutr., November 1, 2002; 132 (11): 3349-3352.

[Abstract] [Full Text] [PDF]

Medline items on this article's topics can be found at http://highwire.stanford.edu/lists/artbytopic.dtl

on the following topics:

Physiology .. Cecum

Physiology .. Digestion

Medicine .. Diet

Medicine .. Bioavailability

Physiology .. Rats

Updated information and services including high-resolution figures, can be found at:

http://ajpgi.physiology.org/cgi/content/full/279/6/G1148

Additional material and information about AJP - Gastrointestinal and Liver Physiology can be found at: http://www.the-aps.org/publications/ajpgi

This information is current as of September 6, 2010 .

AJP - Gastrointestinal and Liver Physiology publishes original articles pertaining to all aspects of research involving normal or abnormal function of the gastrointestinal tract, hepatobiliary system, and pancreas. It is published 12 times a year (monthly) by the American Physiological Society, 9650 Rockville Pike, Bethesda MD 20814-3991. Copyright @ 2000 by the American Physiological Society. ISSN: 0193-1857, ESSN: 1522-1547. Visit our website at http://www.the-aps.org/. 


\title{
Bioavailability of the flavanone naringenin and its glycosides in rats
}

\author{
CATHERINE FELGINES, ${ }^{1}$ ODILE TEXIER,${ }^{1}$ CHRISTINE MORAND,${ }^{2}$ CLAUDINE MANACH, ${ }^{2}$ \\ AUGUSTIN SCALBERT, ${ }^{2}$ FRANÇOISE RÉGERAT, ${ }^{1}$ AND CHRISTIAN RÉMÉSY ${ }^{2}$ \\ ${ }^{1}$ Laboratoire de Pharmacognosie, Faculté de Pharmacie, 63001 Clermont-Ferrand; and ${ }^{2}$ Laboratoire \\ des Maladies Métaboliques et des Micronutriments, Institut National de la Recherche Agronomique \\ de Clermont-Ferrand/Theix, 63122 Saint-Genès Champanelle, France
}

Received 31 March 2000; accepted in final form 5 July 2000

\begin{abstract}
Felgines, Catherine, Odile Texier, Christine Morand, Claudine Manach, Augustin Scalbert, Françoise Régerat, and Christian Rémésy. Bioavailability of the flavanone naringenin and its glycosides in rats. Am $J$ Physiol Gastrointest Liver Physiol 279: G1148-G1154, 2000.-Naringenin, the predominant flavanone in grapefruit, mainly occurs as glycosides such as naringenin-7rhamnoglucoside or naringenin-7-glucoside. This study compared kinetics of absorption of naringenin and its glycosides in rats either after a single flavanone-containing meal or after adaptation to a diet for 14 days. Regardless of the diet, circulating metabolites were glucurono- and sulfoconjugated derivatives of naringenin. The kinetics of absorption of naringenin and naringenin-7-glucoside were similar, whereas naringenin-7-rhamnoglucoside exhibited a delay in its intestinal absorption, resulting in decreased bioavailability. After naringenin-7-glucoside feeding, no glucoside was found in the cecum. However, after feeding naringenin-7-rhamnoglucoside, some naringenin-7-rhamnoglucoside accumulated in cecum before being hydrolyzed by intestinal microflora. Adaptation to flavanone diets did not induce accumulation of plasma naringenin. Moreover, flavanone cecal content markedly decreased after adaptation, and almost no naringenin7-rhamnoglucoside was recovered after naringenin-7-rhamnoglucoside feeding, suggesting that an adaptation of cecal microflora had occurred. Overall, these data indicate that flavanones are efficiently absorbed after feeding to rats and that their bioavailability is related to their glycosidic moiety.

naringenin-7-rhamnoglucoside; naringenin-7-glucoside; intestinal microflora; glucurono- and sulfoconjugated derivatives
\end{abstract}

FLAVONOIDS ARE A WIDELY DISTRIBUTED group of polyphenolic compounds characterized by a common benzo- $\gamma$ pyrone structure. Over 4,000 different flavonoids have been described, and they are categorized into flavonols, flavones, flavanones, isoflavones, catechins, and anthocyanidins. They occur naturally in fruits and vegetables, mainly as flavonoid glycosides, and are thus important constituents of the human diet (5). The daily Western intake of mixed flavonoids has been estimated to be in the range of 0.5 to $1 \mathrm{~g}(20)$, although recent

\footnotetext{
Address for reprint requests and other correspondence: C. Felgines, Laboratoire de Pharmacognosie, Faculté de Pharmacie, 28 place Henri Dunant, BP 38, 63001 Clermont-Ferrand Cedex 1, France (E-mail: Catherine.FELGINES@u-clermont1.fr).
}

investigations have reported that the actual daily intake is frequently lower $(5,14,16)$. Flavonoids have been reported to exhibit a wide range of biological effects, and they may play a dietary role in reducing the risk of chronic diseases such as cardiovascular diseases and cancer $(5,13,16)$.

Flavanones, such as hesperidin and naringin, have a more restricted distribution than other flavonoid compounds and are specific to citrus fruits. Citrus flavonoids have been investigated for biological activity, and anti-inflammatory, anticarcinogenic, and antitumor activities have been reported $(2,24,26)$. Naringin (4',5,7-trihydroxyflavanone-7-rhamnoglucoside or naringenin-7-rhamnoglucoside) is the predominant flavanone in grapefruit (Citrus paradisi) (up to $10 \%$ of the dry weight) and is responsible for the bitterness of grapefruit juices (29).

Although there have been some recent studies on flavone and flavonol bioavailability, data on flavanone metabolism are still scarce. Thus the aim of this work was to evaluate and compare the kinetics of absorption of the aglycone naringenin and of two of its glycosides (naringenin-7-glucoside and naringenin-7-rhamnoglucoside) in rats after a single meal. Moreover, the influence of adaptation to a diet containing naringenin or naringenin-7-rhamnoglucoside on its absorption and metabolism was also investigated.

\section{MATERIALS AND METHODS}

Chemicals. Naringenin, naringenin-7-rhamnoglucoside, $\beta$-glucuronidase/sulfatase from Helix pomatia, and $\beta$-glucuronidase type VII-A from Escherichia coli were purchased from Sigma Chemical (Saint-Quentin-Fallavier, France). Naringenin-7-glucoside and daidzein were purchased from Extrasynthèse (Genay, France).

Animals and diets. Male Wistar rats (Iffa-Credo, L'Arbresle, France) weighing $\sim 170 \mathrm{~g}$ were housed two per cage in temperature-controlled rooms $\left(22^{\circ} \mathrm{C}\right)$, with a dark period from 0800 to 2000 and access to food from 0800 to 1600. They were randomly divided into two groups: nonadapted and adapted rats. Nonadapted rats were fed a semipurified control diet for 14 days (75\% wheat starch, 15\%

\footnotetext{
The costs of publication of this article were defrayed in part by the payment of page charges. The article must therefore be hereby marked "advertisement" in accordance with 18 U.S.C. Section 1734 solely to indicate this fact.
} 
casein, $5 \%$ corn oil, $3.5 \%$ mineral mixture, and $1 \%$ vitamin mixture). Nonadapted rats were then further divided into four groups and received a single experimental meal (25 $\mathrm{g} / \mathrm{rat}$ ) of a control diet (control rats) or of a control diet supplemented with $0.25 \%$ naringenin, $0.38 \%$ naringenin-7glucoside, or $0.5 \%$ naringenin-7-rhamnoglucoside. These amounts correspond to an equivalent supply of aglycone (9.2 $\mathrm{mmol} / \mathrm{kg}$ diet). Adapted rats were divided into three groups and received either the control diet (control rats) or the control diet supplemented with $0.25 \%$ naringenin or $0.5 \%$ naringenin-7-rhamnoglucoside for 14 days. Animals were maintained and handled according to the recommendations of the Institutional Ethics Committee (Institut National de la Recherche Agronomique), in accordance with decree no. 87848.

Sampling procedure. Rats were killed at $3,6,10$, and $24 \mathrm{~h}$ after the beginning of the last experimental meal after being anesthetized with pentobarbital sodium ( $40 \mathrm{mg} / \mathrm{kg}$ body wt). Blood was withdrawn from the abdominal aorta into heparinized tubes. Plasma was acidified with $10 \mathrm{mM}$ acetic acid to prevent loss of flavonoids because the $\mathrm{pH}$ of plasma increases with time, due to the decomposition of bicarbonates, and flavonoids are unstable at a $\mathrm{pH}$ higher than 7.4. For all rats, urine present in the bladder was collected. Urine from rats housed in metabolic cages was collected during the last $24 \mathrm{~h}$. Cecal contents were drained by finger pressure into microfuge tubes and immediately frozen. All samples were stored at $-20^{\circ} \mathrm{C}$ until analysis.

HPLC analysis. Plasma was spiked with daidzein $(21.8$ $\mu \mathrm{M}$ final concentration) as an internal standard and acidified to $\mathrm{pH} 4.9$ with 0.1 volume of $0.58 \mathrm{M}$ acetic acid solution. In the case of enzymatic hydrolysis, samples were incubated for $4 \mathrm{~h}$ at $37^{\circ} \mathrm{C}$ with of $6 \times 10^{6} \mathrm{U} / 1 \beta$-glucuronidase plus $1.8 \times 10^{5}$ $\mathrm{U} / \mathrm{l}$ sulfatase (from $H$. pomatia) or with $10^{6} \mathrm{U} / \mathrm{l} \beta$-glucuronidase (from $E$. coli). All plasma samples were treated by adding 2.8 volumes of acetone, and the resulting mixtures were centrifuged for $5 \mathrm{~min}$ at $12,000 \mathrm{~g}$ at room temperature. Supernatants were evaporated under a nitrogen stream to the initial volume of plasma. Spiking samples with daidzein allowed us to adjust the concentrations according to the extraction efficiency in the plasma (recovery $>85 \%$ ).

For analysis, $20 \mu \mathrm{l}$ of each plasma sample was injected into a $150 \times 4.6-\mathrm{mm}$ Hypersil BDS C18-5 $\mu \mathrm{m}$ column (Life Sciences International, Cergy, France). Elution was performed using water- $\mathrm{H}_{3} \mathrm{PO}_{4}(99.5: 0.5)$ as solvent $A$ and acetonitrile as solvent $B$ at a flow rate of $1.5 \mathrm{ml} / \mathrm{min}$. To quantify flavanones, analyses were carried out with linear gradient conditions from $100 \%$ solvent $A$ to $60 \%$ solvent $A$ for $40 \mathrm{~min}$, with absorbance monitored at $320 \mathrm{~nm}$. Detection of phenolic acids was carried out with linear gradient conditions from $100 \%$ solvent $A$ to $84 \%$ solvent $A$ for $24 \mathrm{~min}$ and then to $54 \%$ solvent $A$ for $15 \mathrm{~min}$, with absorbance monitored at $280 \mathrm{~nm}$.

Cecal contents were extracted with 9 volumes of acetone/ $\mathrm{HCl}(50 \mathrm{mM})$, briefly sonicated, and centrifuged for $5 \mathrm{~min}$ at $12,000 \mathrm{~g}$ at room temperature. After dilution with 5 volumes of acetone, supernatants were analyzed for flavanone contents with the same HPLC system and elution conditions as for plasma.

Twenty-four-hour urine samples and urine collected in the bladder were treated with $\beta$-glucuronidase/sulfatase as plasma, and then 2.8 volumes of acetone were added and the resulting mixtures were centrifuged for $5 \mathrm{~min}$ at $12,000 \mathrm{~g}$ at room temperature. Supernatants were then diluted with 1 volume of acetone, and $10 \mu \mathrm{l}$ of this mixture was injected into a HPLC column and eluted as previously described. In the analysis conditions previously described, the detection limits for flavanones (naringenin, naringenin-7-glucoside, and na- ringenin-7-rhamnoglucoside) were $3 \mu \mathrm{M}$ in plasma and urine and $0.15 \mu \mathrm{mol} / \mathrm{g}$ cecal contents.

Data analysis. Values are given as means $\pm \mathrm{SE}$, and, when appropriate, significance of differences between mean values was determined by ANOVA and multiple-range comparisons (SuperANOVA, Abacus, CA). Values of $P<0.05$ were considered significant.

\section{RESULTS}

HPLC analysis of standard solutions of naringenin, naringenin-7-glucoside, and naringenin-7-rhamnoglucoside indicated that, in our chromatographic conditions, naringenin-7-rhamnoglucoside and naringenin7 -glucoside had similar retention times $(\sim 22.5 \mathrm{~min})$, whereas naringenin eluted at $30.8 \mathrm{~min}$ (Fig. 1, $A$ and $B)$. Representative chromatograms of plasma from control rats and from rats receiving a flavanone are presented in Fig. 1, $C$ and $D$. Whatever the flavanone in the diet, the HPLC profiles of plasma shared five unidentified peaks, referred to as $1,2,3,4$, and 5 (Fig. $1 D$ ), corresponding to conjugated metabolites of naringenin. Neither free flavanone nor aglycone was recovered in rat plasma. The HPLC profile for control rats did not show any trace of these peaks. To confirm that the five unidentified peaks were conjugated forms of naringenin, plasma was treated by $\beta$-glucuronidase/ sulfatase before HPLC analysis. The five peaks present in the nonhydrolyzed plasma disappeared after enzymatic treatment, as shown in Fig. $1 E$, and naringenin was released. Treatment of plasma from rats fed flavanone by a purified $\beta$-glucuronidase released $\sim 5-10 \%$ of total plasma naringenin. The remaining part of naringenin was thus present as sulfo- or glucuronosulfoconjugated derivatives. Furthermore, phenolic acids, such as $p$-hydroxyphenylpropionic acid ( $p$-HPPA), $p$ coumaric acid ( $p$-CA), and $p$-hydroxybenzoic acid ( $p$ HBA), were detected in some plasma samples, but in most samples concentrations were below the limit of quantification.

Regardless of the flavanone diet, HPLC analysis of urine collected in the bladder revealed the presence of similar glucuronosulfoconjugated derivatives as those found in plasma, as well as of some traces of phenolic acids ( $p$-HPPA, $p$-CA, $p$-HBA). These conjugates completely disappeared after $\beta$-glucuronidase/sulfatase hydrolysis as the levels of free phenolic acids and naringenin markedly increased. No naringenin-7-glucoside or naringenin-7-rhamnoglucoside could be detected in urine.

In rats receiving a single experimental meal (nonadapted rats), the appearance of naringenin in plasma was delayed in naringenin-7-rhamnoglucoside-fed rats compared with naringenin- or naringenin-7-glucosidefed rats (Fig. 2). Three hours after the beginning of the meal, a significant concentration of naringenin was recorded in plasma from rats fed naringenin (37.0 \pm $6.2 \mu \mathrm{M})$ and naringenin-7-glucoside $(32.9 \pm 4.3 \mu \mathrm{M})$. In contrast, no naringenin was detected at this time in the plasma from rats fed naringenin-7-rhamnoglucoside. At $10 \mathrm{~h}$, plasma concentrations of naringenin were significantly increased and similar in rats fed naringe- 
Fig. 1. Representative HPLC chromatograms. $A$ and $B$ : naringenin (N), naringenin-7-glucoside (N7G), and naringenin-7-rhamnoglucoside (N7RG) standards. $C$ : plasma from rats fed control diet. $D$ : plasma from naringenin-7rhamnoglucoside-fed rats before hydrolysis. $E$ : plasma from naringenin-7-rhamnoglucosidefed rats after $\beta$-glucuronidase/sulfatase treatment. Detection was performed at $320 \mathrm{~nm}$. 1-5, Metabolites of naringenin (see RESULTS).

$\mathbf{C}$
A $\quad$ B
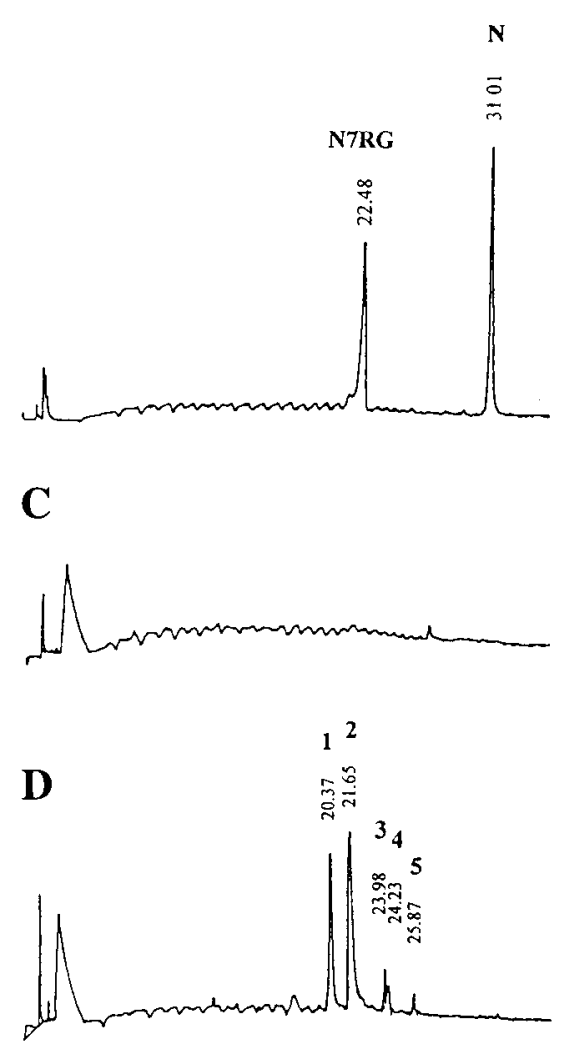

B

N
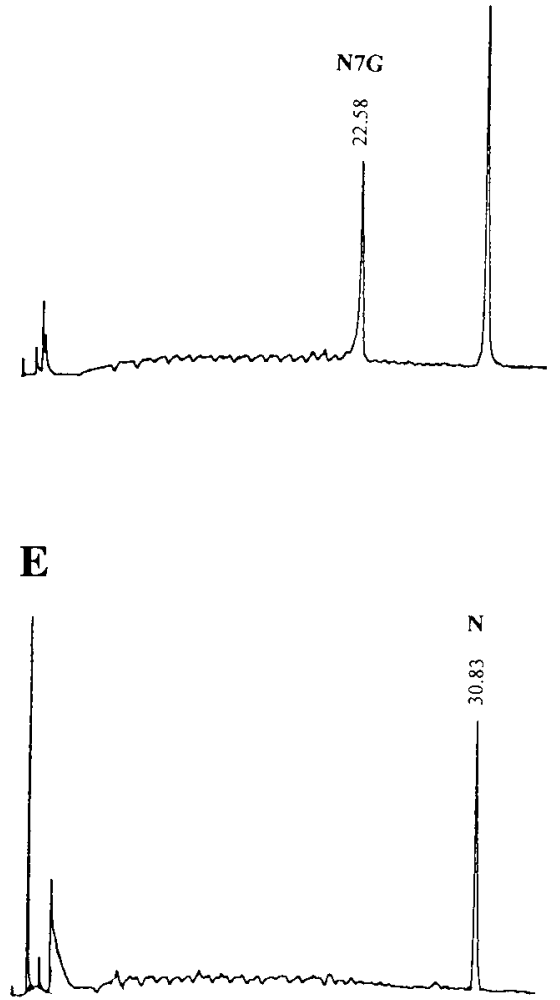

$\operatorname{nin}(128 \pm 2 \mu \mathrm{M})$, naringenin-7-glucoside $(144 \pm 8$ $\mu \mathrm{M})$, or naringenin-7-rhamnoglucoside $(139 \pm 15 \mu \mathrm{M})$. Twenty-four hours after the beginning of the meal, high levels of naringenin $(\sim 68 \mu \mathrm{M})$ were still present in plasma after all flavanone diets. The urinary excretion of naringenin over a 24-h period was significantly higher $(P<0.001)$ in rats fed naringenin or naringe-

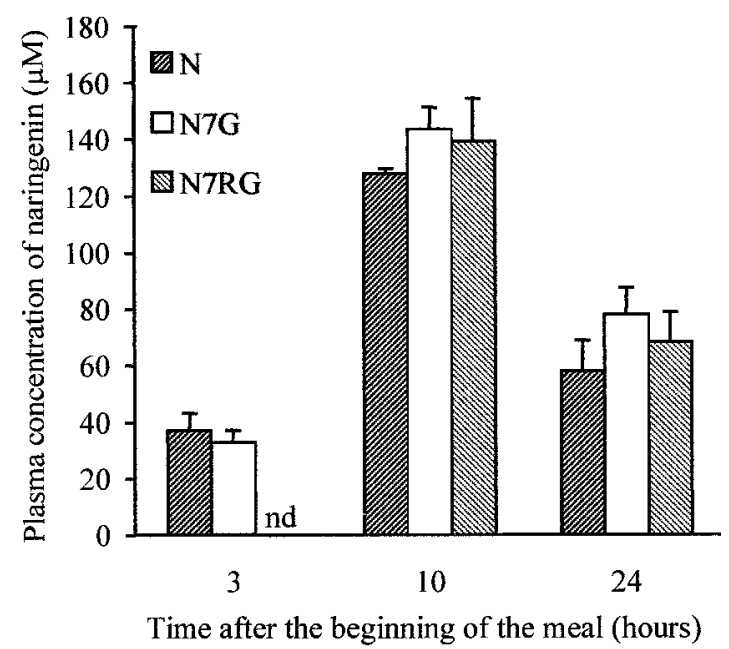

Fig. 2. Evolution of the plasma concentration of naringenin in rats receiving a single meal containing $0.25 \%$ naringenin $(\mathrm{N}), 0.38 \%$ naringenin-7-glucoside (N7G), or $0.5 \%$ naringenin-7-rhamnoglucoside (N7RG). Values are means $\pm \mathrm{SE} ; n=4$. nd, Not detectable. nin-7-glucoside than in rats fed naringenin-7-rhamnoglucoside (Fig. 3).

The presence of flavanones was also studied in cecal contents. Ten hours after the beginning of the experimental meal, naringenin was detected in the cecal contents of rats receiving aglycone or glycoside forms (Fig. 4). No naringenin-7-glucoside was detected in cecal contents from rats fed this glucoside. However, a

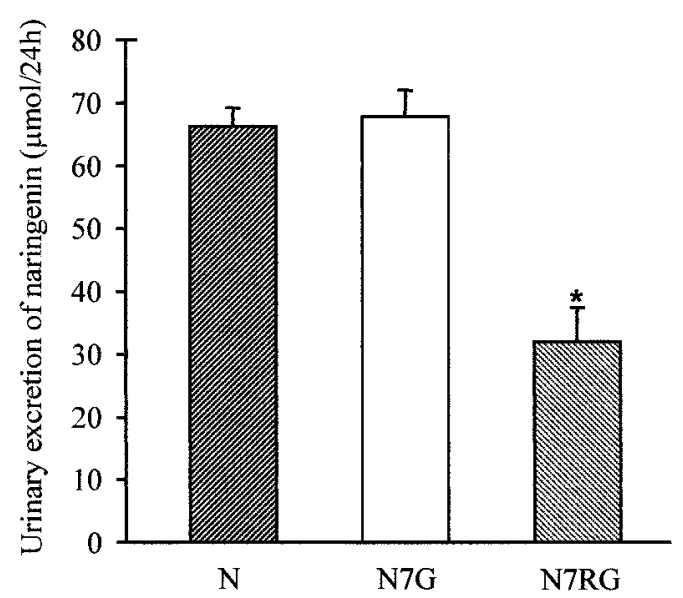

Fig. 3. Twenty-four-hour urinary excretion of naringenin after a single meal containing $0.25 \%$ naringenin $(\mathrm{N}), 0.38 \%$ naringenin-7glucoside $(\mathrm{N} 7 \mathrm{G})$, or $0.5 \%$ naringenin-7-rhamnoglucoside (N7RG). Values are means $\pm \mathrm{SE} ; n=4 . * P<0.001$ vs. $\mathrm{N}$ and N7G. 


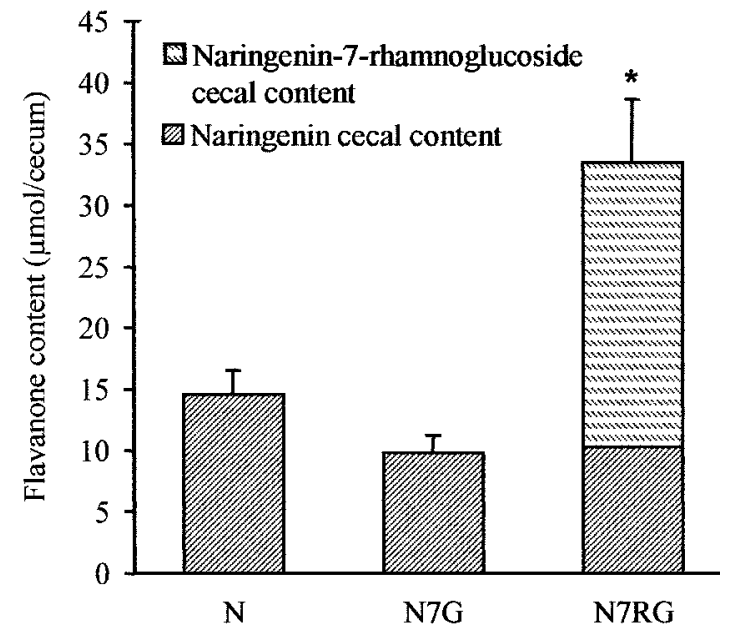

Fig. 4. Cecal contents of naringenin and naringenin-7-rhamnoglucoside $10 \mathrm{~h}$ after the beginning of a single meal containing $0.25 \%$ naringenin $(\mathrm{N}), 0.38 \%$ naringenin-7-glucoside $(\mathrm{N} 7 \mathrm{G})$, or $0.5 \%$ naringenin-7-rhamnoglucoside (N7RG). Values are means $\pm \mathrm{SE} ; n=4$. For total flavanone content in cecum, ${ }^{*} P<0.01$ vs. N and N7G.

large amount of naringenin-7-rhamnoglucoside (23.2 \pm $5.4 \mu \mathrm{mol}$ ) was detected in naringenin-7-rhamnoglucoside-fed rats. The identity of naringenin-7-rhamnoglucoside was verified by using chromatographic conditions that allowed separation of naringenin-7-rhamnoglucoside and naringenin-7-glucoside. In naringenin-7rhamnoglucoside-fed rats, total flavanone accumulation in the cecum was significantly higher $(P<0.01)$ than in rats fed the two other diets.

Figure 5 presents the evolution of plasma naringenin concentration in nonadapted rats or rats adapted to a diet supplemented with naringenin or naringenin-7rhamnoglucoside. In nonadapted rats, there was a progressive increase of naringenin in the plasma until $10 \mathrm{~h}$, followed by a marked decrease between 10 and $24 \mathrm{~h}$. At 3 and $6 \mathrm{~h}$ after the beginning of the single meal, plasma naringenin concentration was significantly higher $(P<0.05)$ after naringenin feeding than after naringenin-7-rhamnoglucoside feeding. A similar evolution of plasma naringenin concentration was observed in adapted rats. In the latter, plasma naringenin concentrations were not significantly different between the two diets except $3 \mathrm{~h}$ after the beginning of the last meal. Moreover, the plasma concentrations of naringenin were significantly higher $(P<0.05)$ after $3 \mathrm{~h}$ and lower $(P<0.05)$ after $24 \mathrm{~h}$ than in the nonadapted rats after the same diet. The highest plasma naringenin concentrations were recorded $10 \mathrm{~h}$ after the beginning of the meal for all the groups and reached $\sim 140 \mu \mathrm{M}$.

Twenty-four-hour urine excretion of naringenin was not significantly different between nonadapted and adapted rats whatever the diet (Table 1). However, it was nearly twofold higher in naringenin-fed rats than in naringenin-7-rhamnoglucoside-fed ones $(P<0.001)$. Urinary excretion of phenolic acids ( $p$-HPPA, $p$-CA, $p$-HBA) was not significantly different between the groups (Table 1). $p$-HPPA was the major phenolic acid
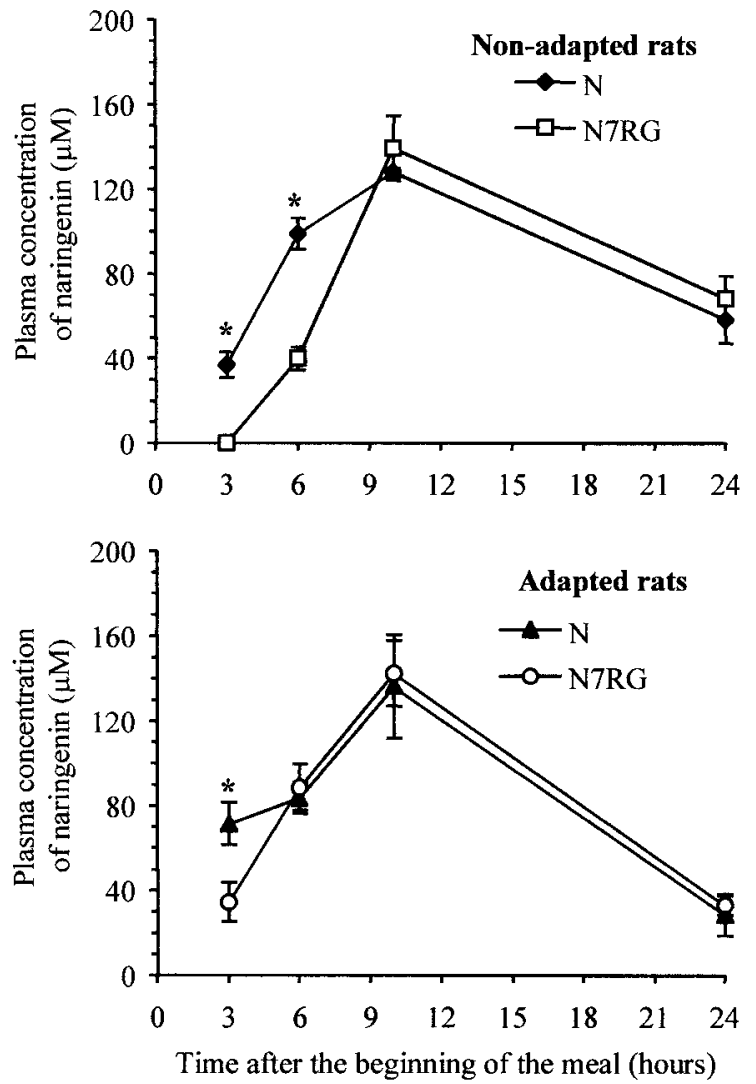

Fig. 5. Evolution of the plasma concentration of naringenin in rats receiving a single meal (nonadapted rats) containing $0.25 \%$ naringenin $(\mathrm{N})$ or $0.5 \%$ naringenin-7-rhamnoglucoside (N7RG) or adapted for 14 days to the same diets. Values are means $\pm \mathrm{SE} ; n=4-6$. ${ }^{*} P<$ 0.05 for $\mathrm{N}$ vs. N7RG.

excreted in urine after flavanone feeding, followed by $p$-CA and $p$-HBA.

Accumulation of flavanones in the cecum is depicted in Fig. 6. After a single meal, cecal naringenin content increased between 3 and $10 \mathrm{~h}$ and then decreased until $24 \mathrm{~h}$ for all of the diets. Naringenin-7-rhamnoglucoside feeding resulted in accumulation of naringenin-7rhamnoglucoside in cecal contents from 3 to $10 \mathrm{~h}$, but no more naringenin-7-rhamnoglucoside was detected $24 \mathrm{~h}$ after the beginning of the meal. In adapted rats, significantly lower quantities of flavanones were de-

Table 1. Twenty-four-hour urinary excretion of naringenin and phenolic acids

\begin{tabular}{llllll}
\hline \hline \multirow{2}{*}{$\begin{array}{c}\text { Urinary } \\
\text { Excretion, } \\
\mu \mathrm{mol} / 24 \mathrm{~h}\end{array}$} & \multicolumn{2}{c}{ Single Meal } & & \multicolumn{2}{c}{ 14-Day Adaptation } \\
\cline { 2 - 3 } \cline { 5 - 6 } & $\mathrm{N}$ & \multicolumn{1}{c}{$\mathrm{N} 7 \mathrm{RG}$} & & $\mathrm{N}$ & \multicolumn{1}{c}{$\mathrm{N} 7 \mathrm{RG}$} \\
\hline Naringenin & $66.2 \pm 3.1$ & $32.0 \pm 5.4^{*}$ & & $58.7 \pm 5.7$ & $23.2 \pm 2.1 \dagger$ \\
$p$-HPPA & $16.9 \pm 2.2$ & $21.9 \pm 1.7$ & & $20.9 \pm 2.4$ & $17.7 \pm 2.5$ \\
$p$-CA & $4.01 \pm 0.49$ & $5.02 \pm 0.64$ & & $4.18 \pm 0.65$ & $3.56 \pm 0.44$ \\
$p$-HBA & $1.24 \pm 0.55$ & $1.78 \pm 0.34$ & & $3.39 \pm 0.68$ & $2.73 \pm 0.44$
\end{tabular}

Values are means $\pm \mathrm{SE} ; n=4-6$ rats. Rats received a single meal containing $0.25 \%$ naringenin $(\mathrm{N})$ or $0.5 \%$ naringenin-7-rhamnoglucoside (N7RG) or were adapted to the same diets for 14 days. $p$-HPPA, $p$-hydroxyphenylpropionic acid; $p$-CA, $p$-coumaric acid; $p$ HBA, $p$-hydroxybenzoic acid. ${ }^{*} P<0.001$ vs. $\mathrm{N}$ diet (single meal); $\dagger P<0.001$ vs. $\mathrm{N}$ diet (14-day adaptation). 

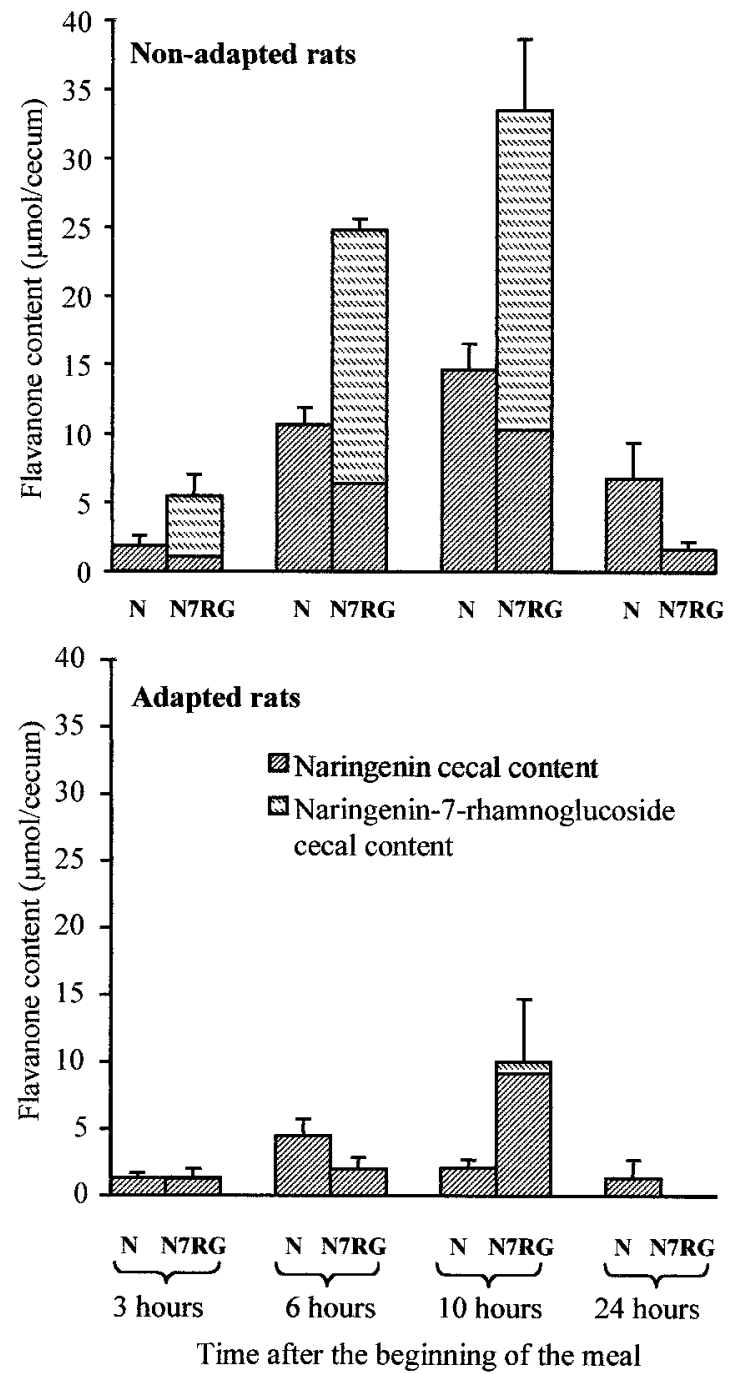

Fig. 6. Cecal contents of naringenin and naringenin-7-rhamnoglucoside in rats receiving a single meal (nonadapted rats) containing $0.25 \%$ naringenin $(\mathrm{N})$ or $0.5 \%$ naringenin-7-rhamnoglucoside (N7RG) or adapted for 14 days to the same diets. Values are means \pm $\mathrm{SE} ; n=4-6$.

tected in cecal contents whatever the time of sampling compared with nonadapted rats. Moreover, only traces of naringenin-7-rhamnoglucoside were detected after naringenin-7-rhamnoglucoside feeding.

\section{DISCUSSION}

Three questions have been addressed in this paper: the structure of the flavanone metabolites in plasma and urine, the impact of the glycosylation of flavanones on their bioavailability, and the influence of adaptation to the flavanone diets on bioavailability. No difference in the structure of the metabolites was observed between the different flavanone diets. Glycosides were not detected in plasma and urine, and the circulating metabolites are glucurono- and/or sulfoconjugated derivatives. Chromatographic profiles show that the same conjugated derivatives are present in plasma and urine. Naringenin was largely esterified to sulfate groups ( $\sim 90 \%)$. Previous studies on rats fed quercetin or catechin have indicated that the main circulating metabolites of quercetin were sulfo and/or glucuronosulfo derivatives, whereas metabolites of catechin were only glucuronidated $(22,27)$. However, catechin sulfates have been reported in the plasma of volunteers given red wine (8). In contrast to catechin and quercetin $(8,22)$, no methylation of naringenin was observed, which was expected because naringenin contains no catechol groups and therefore is not a substrate for catechol-O-methyltransferase (25).

Naringenin was also metabolized into phenolic acids. The same compounds, namely $p$-HPPA, $p$-CA, and $p$ HBA, were detected in plasma and urine as previously reported $(3,11)$, mainly as glucurono or sulfo conjugates. These phenolic acids were formed by the intestinal microflora, as established by previous studies in germ-free or normal rats after parenteral administration of flavonoids (10-12), although it has been suggested that $p$-HBA is essentially a tissue metabolite, probably derived from $p$-CA that was metabolized to $p$-HBA by a mitochondrial enzyme of rat liver $(11,30)$.

In rats fed a single meal, the rate of naringenin appearance in plasma differed between the diets providing aglycone, glucoside, or rhamnoglucoside. Three hours after the beginning of the meal, $\sim 35 \mu \mathrm{M}$ naringenin was found in plasma from rats fed naringenin or its 7-glucoside, whereas at this time naringenin was not detected in any plasma samples from naringenin7-rhamnoglucoside-fed rats. However, at maximal plasma concentrations (at $10 \mathrm{~h}$ ), the plasma concentration of naringenin was of the same order of magnitude regardless of the diet. This underlines the influence of the glycoside moiety on the delay of intestinal absorption of naringenin-7-rhamnoglucoside. These results are in accordance with previous work demonstrating that rutin (quercetin-3-rutinoside) was absorbed more slowly than its aglycone quercetin in rats (21). Studies in humans with various glycosides of quercetin have also demonstrated that rutinoside absorption was delayed compared with the glucoside or aglycone $(15,17)$. Our results thus suggest that absorption of naringenin and naringenin-7-glucoside takes place early in the digestive tract (stomach or small intestine), as previously reported by Choudhury et al. (4). On the other hand, the prolonged time needed for absorption of the rhamnoglucoside suggests that it transits the small intestine and is absorbed from the cecum. The hydrolysis of naringenin-7-rhamnoglucoside may also be necessary before absorption can occur. Colonic microflora can mediate hydrolysis but are likely to degrade a portion of the liberated aglycone in the process (20). The delay in the intestinal absorption of naringenin from naringenin-7-rhamnoglucoside resulted in a marked decrease of naringenin urinary excretion. Thus, despite similar plasma concentrations of naringenin at 10 and $24 \mathrm{~h}$ after all three diets, the bioavailability of naringenin-7-rhamnoglucoside is lower than that for naringenin-7-glucoside or naringenin. Accordingly, biological activity of the glycoside will be lower than that of the aglycone. However, despite a lower 
area of exchange in cecum than in small intestine, absorption of the aglycone from the rhamnoglucoside in the cecum seems to be quantitatively of some importance.

Examination of cecal contents has shown that no naringenin-7-glucoside was found in cecum after naringenin-7-glucoside feeding, thus indicating that the glucoside moiety of naringenin-7-glucoside had been hydrolyzed in the proximal part of the intestine or by the cecal microflora. On the other hand, after naringenin-7-rhamnoglucoside feeding, this glycoside accumulated in the cecum in significant amounts and was accompanied by some naringenin, but no glucoside had been detected. This suggests that a small part of this glycoside had been hydrolyzed to its corresponding aglycone by glycosidases produced by intestinal bacteria $(11,19)$. All of these results are in accordance with a recent work showing that the human small intestine possesses a cytosolic $\beta$-glucosidase capable of efficiently hydrolyzing naringenin-7-glucoside but not naringenin-7-rhamnoglucoside (7). Moreover, it has been shown in rats that the hydrolysis of flavonoid glucosides occurs mainly in the jejunum (18). In the same way, it has been reported that quercetin was absorbed after in situ perfusion of rat small intestine, whereas rutin was not (6).

Adaptation to naringenin- or naringenin-7-rhamnoglucoside-containing diets for 14 days did not result in a marked accumulation of plasma naringenin. Adapted animals showed a higher plasma naringenin concentration $3 \mathrm{~h}$ after the beginning of the final meal compared with nonadapted rats; however, the plasma concentration also declined faster between 10 and $24 \mathrm{~h}$. This result contrasts with previous studies on flavonols showing that, after adaptation of rats to a $0.2 \%$ quercetin diet, plasma concentration of quercetin metabolites was quite constant along the nycthemere $(\sim 100$ $\mu \mathrm{M}$ ), and this concentration was higher than those obtained after a single quercetin meal (21). Twentyfour-hour urinary excretion of naringenin and phenolic acids was similar in adapted and nonadapted rats. This means that, during a 24-h period, similar amounts of flavanone were absorbed along the digestive tract as well as hydrolyzed in cecum. However, adaptation to the flavanone diet did affect flavanone cecal content. Indeed, in contrast to what happened in nonadapted rats, almost no flavanone accumulated into the cecum in adapted rats. In these rats, cecal microflora have adapted and thus hydrolyzed flavanones that reach the large intestine into aglycone and phenolic acids more rapidly than in nonadapted rats. Aglycone and phenolic acids were then absorbed. This explains why, despite similar amounts of flavanones that enter the cecum, few intact flavanones were recovered into cecal contents in adapted rats.

Overall, our results have demonstrated that flavanones were efficiently absorbed after being fed to rats. After a single meal, the percentage of naringenin recovered in urine (calculated as the ratio of naringenin excreted to naringenin ingested) was $\sim 28,31$, and $14 \%$ after aglycone, glucoside, or rhamnoglucoside intake, respectively. A recent study (4) has reported that total urinary recovery of naringenin after gavage with naringenin or naringenin-7-glucoside was $\sim 10 \%$. Discrepancies between these results could be related to the mode of flavanone administration. Indeed, feeding rats with a semipurified diet supplemented with flavanone allows an increasing duration of intestinal absorption, whereas after gavage with a flavanone solution in overnight-fasted rats (4), the bolus of flavanone transits more rapidly along the digestive tract. Moreover, in humans fed naringenin-7-rhamnoglucoside or grapefruit juices, naringenin-7-rhamnoglucoside bioavailability was between 5 and $9 \%(1,9)$. In our study, the magnitude of urinary excretion was similar with naringenin and naringenin-7-glucoside, suggesting that the glucose moiety did not affect the bioavailability. It should be noted that the delayed absorption of the rhamnoglucoside affects the urinary excretion, whereas the plasma concentrations were of the same magnitude during the postabsorptive period.

Compared with studies dealing with the bioavailability of flavonols in rats $(21,23)$, our data show that flavanones are more efficiently absorbed. Since naringenin-7-rhamnoglucoside is present in grapefruit and grapefruit juices in high amounts (from 100 to $500 \mathrm{mg} / \mathrm{l}$ in juices, depending on grapefruit variety) (28), its consumption by humans is quantitatively of importance. Therefore, evaluation of flavanone bioavailability in humans would be of some interest.

We thank Catherine Besson for her expert technical assistance.

\section{REFERENCES}

1. Ameer B, Weintraub RA, Johnson JV, Yost RA, and Rouseff RL. Flavanone absorption after naringin, hesperidin, and citrus administration. Clin Pharmacol Ther 60: 34-40, 1996.

2. Benavente-Garcia O, Castillo J, Marin FR, Ortuño A, and Del Rio JA. Uses and properties of citrus flavonoids. J Agric Food Chem 45: 4505-4515, 1997.

3. Booth AN, Jones FT, and De Eds F. Metabolic and glucosuria studies on naringin and phloridzin. J Biol Chem 233: 280-282, 1958.

4. Choudhury R, Chowrimootoo G, Srai K, Debnam E, and Rice-Evans CA. Interactions of the flavonoid naringenin in the gastrointestinal tract and the influence of glycosylation. Biochem Biophys Res Commun 265: 410-415, 1999.

5. Cook NC and Samman S. Flavonoids-chemistry, metabolism, cardioprotective effects, and dietary sources. $J$ Nutr Biochem 7: 66-76, 1996.

6. Crespy V, Morand C, Manach C, Besson C, Demigné C, and Rémésy C. Part of quercetin absorbed in the small intestine is conjugated and further secreted in the intestinal lumen. Am J Physiol Gastrointest Liver Physiol 277: G120-G126, 1999.

7. Day AJ, Du Pont MS, Ridley S, Rhodes M, Rhodes MJC, Morgan MRA, and Williamson G. Deglycosylation of flavonoid and isoflavonoid glycosides by human small intestine and liver $\beta$-glucosidase activity. FEBS Lett 436: 71-75, 1998.

8. Donovan JL, Bell JR, Kasim-Karakas S, German JB, Walzem RL, Hansen RJ, and Waterhouse AL. Catechin is present as metabolites in human plasma after consumption of red wine. J Nutr 129: 1662-1668, 1999.

9. Fuhr $\mathbf{U}$ and Kummert AL. The fate of naringin in humans: a key to grapefruit juice-drug interactions? Clin Pharmacol Ther 58: 365-373, 1995.

10. Griffiths LA and Barrow A. Metabolism of flavonoid compounds in germ-free rats. Biochem J 130: 1161-1162, 1972.

11. Griffiths LA and Smith GE. Metabolism of apigenin and related compounds in the rat. Metabolite formation in vivo and 
by the intestinal microflora in vitro. Biochem $J$ 128: 901-911, 1972.

12. Hackett AM, Marsh I, Barrow A, and Griffiths LA. The biliary excretion of flavanones in the rat. Xenobiotica 9: 491-501, 1979.

13. Havsteen B. Flavonoids, a class of natural products of high pharmacological potency. Biochem Pharmacol 32: 1141-1148, 1983.

14. Hertog MGL, Feskens EJM, Hollman PCH, Katan MB, and Kromhout D. Dietary antioxidant flavonoids and risk of coronary heart disease: the Zutphen Elderly Study. Lancet 342: 1007-1011, 1993.

15. Hollman PCH, de Vries JHM, van Leeuwen SD, Mengelers MJB, and Katan MB. Absorption of dietary quercetin glycosides and quercetin in healthy ileostomy volunteers. Am J Clin Nutr 62: 1276-1282, 1995.

16. Hollman PCH and Katan MB. Dietary flavonoids: intake, health effects and bioavailability. Food Chem Toxicol 37: 937$942,1999$.

17. Hollman PCH, van Trijp JMP, Buysman NCP, Gaag MS, Mengelers MJB, de Vries JHM, and Katan MB. Relative bioavailability of the antioxidant flavonoid quercetin from various foods in man. FEBS Lett 418: 152-156, 1997.

18. Ioku K, Pongpiriyadacha Y, Konishi Y, Takei Y, Nakatani $\mathbf{N}$, and Terao J. $\beta$-Glucosidase activity in the rat small intestine toward quercetin monoglucosides. Biosci Biotechnol Biochem 62: 1428-1431, 1998.

19. Kim DH, Jung EA, Sohng IS, Han JA, Kim TH, and Han MJ. Intestinal bacteria metabolism of flavonoids and its relation to some biological activities. Arch Pharmacol Res (Seoul) 21: 17-23, 1998.

20. Kühnau J. The flavonoids. A class of semi-essential food components: their role in human nutrition. World Rev Nutr Diet 24: 117-191, 1976.

21. Manach C, Morand C, Demigné C, Texier O, Régerat F, and Rémésy C. Bioavailability of rutin and quercetin in rats. FEBS Lett 409: 12-16, 1997.
22. Manach C, Texier O, Morand C, Crespy V, Régerat F, Demigné $\mathbf{C}$, and Rémésy $\mathbf{C}$. Comparison of the bioavailability of quercetin and catechin in rats. Free Radic Biol Med 27: 1259-1266, 1999.

23. Manach C, Texier O, Régerat F, Agullo G, Demigné C, and Rémésy C. Dietary quercetin is recovered in rat plasma as conjugated derivatives of isorhamnetin and quercetin. $J$ Nutr Biochem 7: 375-380, 1996.

24. Middleton E and Kandaswami C. The impact of plant flavonoids on mammalian biology: implications for immunity, inflammation and cancer. In: The Flavonoids: Advances in Research Since 1986, edited by Harborne JB. London: Chapman \& Hall, 1994, p. 619-652.

25. Monks TJ, Hanzlik RP, Cohen GM, Ross D, and Graham DG. Quinone chemistry and toxicity. Toxicol Appl Pharmacol 112: 2-16, 1992

26. Montanari A, Chen J, and Widmer W. Citrus flavonoids: a review of past biological activity against disease. Discovery of new flavonoids from Dancy tangerine cold pressed peel oil solids and leaves. In: Flavonoids in the Living System, edited by Manthey J and Buslig B. New York: Plenum, 1998, p. 103-116.

27. Morand C, Crespy V, Manach C, Besson C, Demigné C, and Rémésy C. Plasma metabolites of quercetin and their antioxidant properties. Am J Physiol Regulatory Integrative Comp Physiol 275: R212-R219, 1998.

28. Mouly PP, Arzouyan CR, Gaydou EM, and Estienne JM. Differentiation of citrus juices by factorial discriminant analysis using liquid chromatography of flavanone glycosides. J Agric Food Chem 42: 70-79, 1994.

29. Ortuño A, Garcia-Puig D, Fuster MD, Pérez ML, Sabater F, Porras I, Garcia-Lidon A, and Del Rio AJ. Flavanone and nootkatone levels in different varieties of grapefruit and pummelo. J Agric Food Chem 43: 1-5, 1995.

30. Ranganathan S and Ramasarma T. Enzymic formation of $p$-hydroxybenzoate from $p$-hydroxycinnamate. Biochem $J$ 122: 487-493, 1971 